\title{
Objective Versus Self-Reported Adherence to Airway Clearance Therapy in Cystic Fibrosis
}

\author{
Gabriela R Oates, Irena Stepanikova, Steven M Rowe, Stephanie Gamble, \\ Hector H Gutierrez, and William T Harris
}

\begin{abstract}
BACKGROUND: Historically, studies of adherence to airway clearance therapy in cystic fibrosis (CF) have relied on self-reporting. We compared self-reported airway clearance therapy adherence to actual usage data from home high-frequency chest wall compressions (HFCWC) vests and identified factors associated with overestimation of adherence in self-reports. METHODS: Pediatric patients who perform airway clearance therapy with a HFCWC vest were eligible to participate. Objective adherence data were obtained from the HFCWC device, which records cumulative utilization time. Two readings at least 5 weeks apart were collected. Objective adherence was recorded as a ratio of mean-to-prescribed daily use (\%). Self-reported adherence data were collected with a caregiver survey at enrollment. Adherence rates were categorized as low $(<35 \%$ of prescribed), moderate (36-79\% of prescribed), and high ( $\geq 80 \%$ of prescribed). An overestimation was present when self-reported adherence was at least one category higher than objective adherence. RESULTS: In the final sample $(N=110)$, mean adherence by usage data was $61 \%$. Only $35 \%$ of subjects $(n=38)$ were highly adherent, and $28 \%(n=31)$ were low adherent. In contrast, $65 \%$ of subjects $(n=72)$ reported high adherence and only $8 \%(n=9)$ reported low adherence $(P<.001)$. Nearly half of self-reports $(46 \%)$ overestimated adherence. In a multiple regression analysis, overestimation was associated with multiple airway clearance therapy locations (odds ratio 7.13, 95\% CI 1.16-43.72, $P=.034$ ) and prescribed daily use $\geq 60$ min (odds ratio $3.85,95 \%$ CI $1.08-13.76, P<.038)$. Among subjects with prescribed daily airway clearance therapy $\geq 60 \mathrm{~min}$, the odds of overestimating adherence increased 3-fold (odds ratio $3.04,95 \%$ CI 1.17-7.87, $P=.02$ ) in a lower-income $(<\$ \mathbf{5 0 , 0 0 0 / y})$ environment. CONCLUSIONS: Self-reports overestimated actual adherence to airway clearance therapy, and the overestimation increased with treatment occurring in multiple households and prescribed therapy duration. Among participants with prescribed airway clearance therapy $\geq 60 \mathrm{~min}$, overestimation increased with lower income. Objective measures of adherence are needed, particularly for lower-income children and those receiving treatments in multiple locations. Key words: adherence; airway clearance; chest physical therapy; high-frequency chest wall compressions; cystic fibrosis. [Respir Care 2019;64(2):176-181. (C) 2019 Daedalus Enterprises]
\end{abstract}

\section{Introduction}

Adherence, defined as the extent to which a person's behavior (in terms of taking medications, following diets,

Drs Oates, Rowe, Gutierrez, and Harris are affiliated with the Division of Pediatric Pulmonary and Sleep Medicine, as well as the Gregory Fleming James Cystic Fibrosis Research Center, University of Alabama at Birmingham, Alabama. Dr Rowe is also affiliated with the Departments of Medicine and Cell Developmental and Integrative Biology, University of Alabama at Birmingham. Dr Stepanikova is affiliated with the Department of Sociology, University of Alabama at Birmingham and Research Center for Toxic Com- or executing lifestyle changes) coincides with medical or health advice, ${ }^{1}$ involves actions and intentions that are difficult to quantify. ${ }^{2}$ In the absence of established standards for assessment, adherence has been measured in a variety of ways, each with its own strengths and limita-

pounds in the Environment (RECETOX), Masaryk University, Czech Republic. Ms Gamble is affiliated with Children's Hospital of Alabama, Birmingham, Alabama.

The authors disclose a relationship with the UAB Gregory Fleming James Cystic Fibrosis Research Center. 
tions. ${ }^{3}$ Overall, the available measures are either subjective, such as self-reports by patients or caregivers, or objective, such as missed appointments, pill counts, electronic monitoring, chart reviews, and serum assays of drug levels. In subjective measures, data are easily collected, but there is the potential for information bias or recall bias, resulting in inadequate reliability and overestimation of adherence. ${ }^{4-7}$

Airway clearance therapy is a standard component of the daily therapeutic regimen ${ }^{8,9}$ for patients with cystic fibrosis (CF), the second most common life-shortening genetic disorder in the United States. ${ }^{10}$ Adherence to airway clearance therapy in CF has been estimated at $40-$ $60 \%$ by subjective, self-reported measures. ${ }^{11-13}$ Although disagreement between self-reported and actual adherence has been reported for other components of the $\mathrm{CF}$ regimen (eg, nebulizer treatments), ${ }^{14}$ assessments of airway clearance therapy have relied historically on self-reports. This study investigated the discrepancy between self-reported and objectively measured adherence to airway clearance therapy in pediatric patients with $\mathrm{CF}$. We compared the 2 adherence measures using data from the patients' home airway clearance therapy equipment, a high-frequency chest wall compression (HFCWC) vest, and we identified factors associated with overestimation of self-reported adherence.

Objectively measured adherence to airway clearance therapy in pediatric patients with $\mathrm{CF}$ has been associated with patient age and prescribed therapy duration, ${ }^{15}$ as well as maternal education, household income, and the number of adults in the household. ${ }^{16}$ We expected that these factors will also be impactful when comparing self-reported and objective adherence measures in this population. We proposed 2 study hypotheses: self-reports will overestimate actual adherence to airway clearance therapy, and overestimation will be positively associated with prescribed treatment duration, patient age, lower parental education, lower household income, and fewer adults in the household.

\section{Methods}

\section{Study Population}

Pediatric patients at the University of Alabama at Birmingham CF Center who perform airway clearance therapy with the HFCWC vest $(n=161)$ were eligible to participate. Vest compressors feature a built-in chronom-

Correspondence: Gabriela R Oates, ACC 620, $16007^{\text {th }}$ Avenue South, Birmingham, AL 35233. E-mail: goates@uab.edu.

DOI: $10.4187 /$ respcare.06436

\section{QUICK LOOK}

\section{Current knowledge}

Studies of adherence to airway clearance therapy in CF have relied on self-reporting, which may overestimate actual adherence rates. Factors associated with overestimation of self-reported adherence to airway clearance in this population have not been identified.

\section{What this paper contributes to our knowledge}

We compared self-reported adherence to actual usage data from home high-frequency chest wall compression vests and found that nearly half of self-reports overestimated actual adherence. The overestimation increased with treatment in multiple households and prescribed treatment duration. Among subjects with prescribed treatment of at least $60 \mathrm{~min}$, overestimation increased with lower income. Objective measures of adherence are needed, particularly in lower-income patients and those receiving treatments in multiple locations.

eter that records cumulative device utilization time, offering an accurate, objective adherence measure. HFCWC is the most common method for airway clearance therapy in the United States, used by $86 \%$ of patients with $\mathrm{CF}$, age $6-18$ y. ${ }^{10}$

Of all eligible patients, $126(78 \%)$ were invited to participate in the study. Of those who enrolled $(n=120)$, $116(97 \%)$ completed the study. Missing data resulted in the exclusion of $5 \%$ of observations $(n=6)$. The final analyses included 110 subjects. The study was approved by the University of Alabama at Birmingham Institutional Review Board for Human Use (Protocol X140124004).

\section{Data Collection}

Objective adherence data were obtained from the subject's home HFCWC device. Two readings were recorded: the first within $2 \mathrm{~d}$ of study enrollment, and the second approximately 5 weeks after baseline. The difference between the 2 readings, divided by the number of days between them, provided an average daily use of the HFCWC vest. In-patient days were subtracted from the number of days between readings, if applicable. Self-reported adherence data were collected with a paper questionnaire at study enrollment. The survey also collected data on the family's demographics, socioeconomic characteristics, and health behaviors. Clinical data were abstracted from the CF Patient Registry. 


\section{Adherence Measures}

Objective adherence rate was represented as a ratio of mean-to-prescribed daily use (\%). Prescribed daily use was provided by the respiratory therapist. The self-reported adherence measure was adopted from the validated Treatment Adherence Questionnaire-CF. ${ }^{17}$ This wellestablished tool has strong psychometrics, including high test-retest reliability and parent-adolescent agreement. Only questions pertaining to airway clearance were used: "In a typical week, how often does your child do airway clearance?" (Not at all; 1-2 times per week; 3 times per week; 4 or more times per week; Once a day; Twice a day; Three or more times per day); and "In a typical week, how many minutes does your child spend doing each airway clearance treatment?" $(0 \mathrm{~min} ; 5 \mathrm{~min} ; 10 \mathrm{~min} ; 15 \mathrm{~min}$; $20 \mathrm{~min}$; 25 or more min). Self-reported adherence rates were calculated based on responses about frequency and duration of treatments. Both objective and self-reported adherence were coded in 3 categories: low $(<35 \%$ of prescribed), moderate (36-79\% of prescribed), and high ( $\geq 80 \%$ of prescribed) in accordance with previously used cut-offs. ${ }^{16,18}$ The discrepancy between self-reported and objective adherence was coded as " 1 = Yes" when the difference between the 2 measures was at least 1 category (eg, high vs moderate or moderate vs low).

\section{Control Variables}

Data on caregiver age, race, gender, educational attainment, annual household income, health insurance (private/public), marital status, number of adults in the household, and location of airway clearance therapy treatments were collected with a paper survey at study intake. Clinical data were abstracted from the CF Patient Registry. Lung function was reported as $\mathrm{FEV}_{1} \%$ predicted, with values estimated based on Wang equations. ${ }^{19}$

\section{Statistical Analysis}

Univariate statistics, including means, standard deviations, frequencies, and proportions, were obtained for all non-missing cases. Bivariate relationships were estimated with analysis of variance, simple logistic regression, or cross-tabulation using the Pearson chi square test for cells with $>5$ observations and Fisher exact statistics for cells with $\leq 5$ observations. Adherence overestimation was further examined with multivariable logistic regression. Factors in the model included variables with a significance level $P<.10$ in the bivariate analyses. Statistical tests were 2-tailed and were conducted using a 5\% significance level $(\alpha=.05)$. Analyses were performed with Stata software, version 14 (StataCorp, College Station, Texas).
Table 1. Characteristics of Study Participants $(N=110)$

\begin{tabular}{|c|c|}
\hline Variable & $\%$ or Mean $(\mathrm{SD})$ \\
\hline \multicolumn{2}{|l|}{ Caregiver characteristics } \\
\hline Age, y & $41.1(8.0)$ \\
\hline White & 91.8 \\
\hline Female & 84.6 \\
\hline Married/cohabiting & 85.5 \\
\hline Paternal education $\leq$ high school & 34.6 \\
\hline Maternal education $\leq$ high school & 20.9 \\
\hline Household income $<\$ 50,000$ & 40.9 \\
\hline Public health insurance & 35.5 \\
\hline One-adult households & 10.9 \\
\hline \multicolumn{2}{|l|}{ Patient characteristics } \\
\hline Age, y & $11.2(4.7)$ \\
\hline F508del homozygous genotype & 52.7 \\
\hline P. aeruginosa ever & 36.4 \\
\hline CF-related diabetes & 14.6 \\
\hline Depressive symptoms & 12.7 \\
\hline Other comorbidities & 70.0 \\
\hline \multicolumn{2}{|l|}{ Lung function, $\mathrm{FEV}_{1} \%$ predicted } \\
\hline$<85$ & 21.8 \\
\hline $85-99$ & 34.6 \\
\hline$\geq 100$ & 27.3 \\
\hline N/A $($ age $<6$ y)* & 16.4 \\
\hline \multicolumn{2}{|l|}{ Airway clearance therapy characteristics } \\
\hline Prescribed daily duration $\geq 60 \mathrm{~min}$ & 83.6 \\
\hline Multiple locations & 9.1 \\
\hline \multicolumn{2}{|l|}{ HFCWC vest type } \\
\hline Hill-Rom, TheVest & 86.4 \\
\hline Respirtech, InCourage System & 11.8 \\
\hline Electromed, SmartVest & 1.8 \\
\hline \multicolumn{2}{|l|}{ Adherence } \\
\hline Objective (mean-to-prescribed daily use, $\%$ ) & $60.6(31.0)$ \\
\hline$\leq 35 \%$ & 28.2 \\
\hline $36 \%-79 \%$ & 37.3 \\
\hline$\geq 80 \%$ & 34.6 \\
\hline \multicolumn{2}{|l|}{ Self-reported } \\
\hline$\leq 35 \%$ & 8.2 \\
\hline $36 \%-79 \%$ & 26.4 \\
\hline$\geq 80 \%$ & 65.5 \\
\hline Overestimation (self-reported $>$ objective) & 46.5 \\
\hline $\begin{array}{l}N=110 \text { subjects } \\
* \text { Subject was age-ineligible for pulmonary function test. }\end{array}$ & \\
\hline
\end{tabular}

\section{Results}

\section{Characteristics of the Sample}

The characteristics of the sample are presented in Table 1. Mean caregiver age was $41 \mathrm{y}$, and mean subject age was $11 \mathrm{y}$. The majority of caregivers were non-Hispanic white (92\%), female (85\%), and married/cohabiting (86\%). Thirty-five percent of fathers and $21 \%$ of mothers had a highschool education or less; $41 \%$ of households had income 


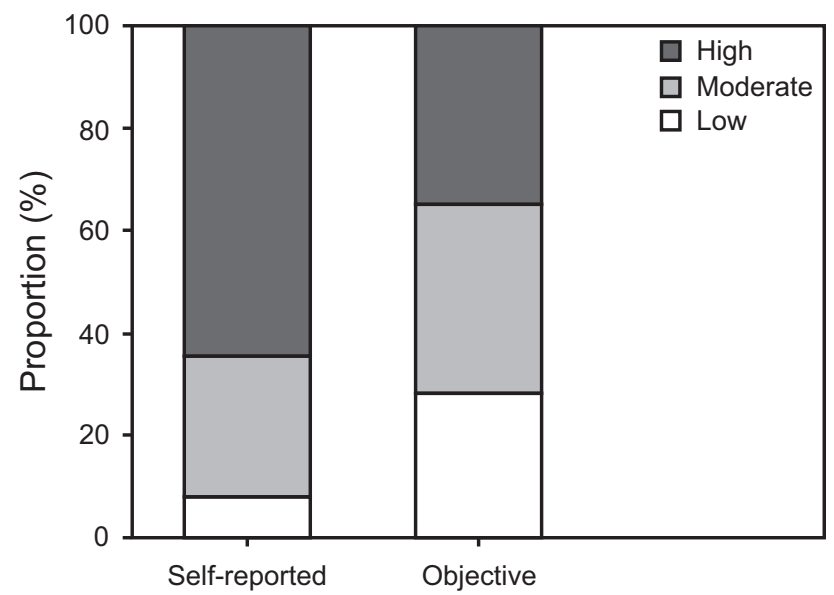

Fig. 1. Self-reported vs objective adherence (\% of prescribed daily therapy) to airway clearance therapy. $P<.001$ between self-reported and objective data for each category of adherence. High adherence: $>80 \%$ of prescribed daily therapy, Moderate adherence: $36-79 \%$ of prescribed daily therapy, and Low adherence: $\leq 35 \%$ of prescribed daily therapy.

$<\$ 50,000 / y, 36 \%$ had public health insurance, and $11 \%$ were single-adult households. In $9 \%$ of cases, airway clearance therapy took place in multiple locations (ie, in more than one household, as with divorced parents or with care split between parents and grandparents). The majority of subjects (84\%) had prescribed daily airway clearance therapy of $60 \mathrm{~min}$ or more, and the majority of vests (86\%) were The Vest (Hill-Rom, Batesville, Indiana).

\section{Adherence Rates}

Mean time between HFCWC vest utilization readings was $37 \mathrm{~d}$. On the basis of utilization data, the mean adherence rate was $61 \%$ of prescribed. Only $35 \%$ of all subjects $(n=38)$ were highly adherent $(\geq 80 \%$ of prescribed), and $28 \%(n=31)$ were low-adherent $(\leq 35 \%$ of prescribed). On the basis of caregiver self-report, $66 \%$ of subjects $(n=72)$ were highly adherent, and $8 \%(n=9)$ were low adherent. Nearly half of caregivers $(47 \%)$ assessed their adherence inaccurately $(P<.001)$ (Fig. 1). These results support our hypothesis that self-reports overestimate actual adherence to airway clearance therapy.

\section{Overestimation of Self-Reported Adherence}

Table 2 shows results of bivariate analysis of adherence overestimation by caregiver, patient and airway clearance therapy characteristics included in Table 1 . Only variables with $P<.10$ are presented. Among caregiver characteristics, overestimation of adherence was associated with income $<\$ 50,000 / y$ (odds ratio [OR] 2.56, 95\% CI 1.17 $5.59, P=.02)$. Clinical phenotype was not significantly
Table 2. Factors Associated with Overestimation of Self-Reported Adherence

\begin{tabular}{lll}
\hline \hline & $\begin{array}{c}\text { Odds Ratio } \\
(95 \% \mathrm{CI})\end{array}$ & $P$ \\
\hline $\begin{array}{l}\text { Caregiver characteristics } \\
\text { Age }\end{array}$ & $0.95(0.90-1.00)$ & .050 \\
$\quad$ Income $<\$ 50,000$ & $2.56(1.17-5.59)$ & .02 \\
Patient characteristics & $0.48(0.22-1.07)$ & .07 \\
$\quad \begin{array}{l}P . \text { aeruginos } a \text { ever } \\
\text { FEV } \% \text { pred. }>100 \%\end{array}$ & $0.48(0.20-1.14)$ & .10 \\
Airway clearance therapy characteristics & & \\
$\quad \begin{array}{l}\text { Multiple airway clearance therapy locations } \\
\text { Prescribed duration } \geq 60 \text { min }\end{array}$ & $5.30(1.07-26.24)$ & .041 \\
& $1.03(0.99-1.07)$ & .09 \\
\hline$N=110$ subjects. Only variables with $P<.10$ are presented. & & \\
\hline
\end{tabular}

Table 3. Multiple Logistic Regression of Adherence Overestimation

\begin{tabular}{lll}
\hline \hline \multicolumn{1}{c}{ Variables } & $\begin{array}{c}\text { Odds Ratio } \\
(95 \% \mathrm{CI})\end{array}$ & $P$ \\
\hline Multiple airway clearance therapy locations & $7.13(1.16-43.72)$ & .034 \\
Prescribed duration $\geq 60 \mathrm{~min}$ & $3.85(1.08-13.76)$ & .038 \\
Caregiver age & $0.97(0.91-1.02)$ & .23 \\
Income $<\$ 50,000$ & $1.85(0.78-4.35)$ & .16 \\
$P$. aeruginosa ever & $0.64(0.26-1.62)$ & .35 \\
FEV $_{1} \%$ pred $>100 \%$ & $0.50(0.19-1.35)$ & .17 \\
\hline$N=110$ subjects. & & \\
Likelihood ratio chi square $(6)=21.09, P<.01$. & & \\
\hline
\end{tabular}

associated with increased odds of inaccurate self-reported adherence. Nonsignificant trends toward agreement between objective and subjective adherence were observed in subjects with a history of $P$. aeruginosa (OR 0.48 , $P=.07)$ and those with a $\mathrm{FEV}_{1}>100 \%$ predicted (OR $0.48, P=.10$ ). Having multiple locations for airway clearance therapy delivery was significantly associated with adherence overestimation (OR 5.30, 95\% CI 1.07-26.24, $P=.041)$.

Table 3 presents results from multiple logistic regression of adherence overestimation. In the model, which included all variables with $P<.10$ in the bivariate analyses, multiple airway clearance therapy locations (OR 7.13, 95\% CI 1.16-43.72, $P=.034$ ) and prescribed airway clearance therapy duration of $\geq 60 \mathrm{~min}$ (OR $3.85,95 \% \mathrm{CI}$ $1.08-13.76, P=.038$ ) were statistically significant predictors of overestimation, increasing the risk of inaccurate self-reports approximately 7-fold and 4-fold, respectively.

Among the subgroup of subjects with prescribed daily airway clearance therapy of $\geq 60 \mathrm{~min}$, household income $<\$ 50,000 / y$ was associated with a 3 -fold increase in the odds of adherence overestimation (OR 3.04, 95\% CI 1.17- 
Table 4. Adherence Overestimation When Prescribed Daily Treatment Is $\geq 60 \mathrm{~min}$

\begin{tabular}{lll}
\hline \hline \multicolumn{1}{c}{ Variables } & \multicolumn{1}{c}{$\begin{array}{c}\text { Odds Ratio } \\
(95 \% \mathrm{CI})\end{array}$} & $P$ \\
\hline Multiple airway clearance therapy locations & $6.88(0.75-63.34)$ & .09 \\
Caregiver age & $0.95(0.90-1.01)$ & .13 \\
Income $<\$ 50,000$ & $3.04(1.17-7.87)$ & .02 \\
$P$. aeruginosa ever & $0.73(0.26-2.01)$ & .54 \\
FEV $1 \%$ pred. $>100 \%$ & $0.76(0.26-2.20)$ & .61 \\
${ } }$ & & \\
Likelihood ratio chi square $(5)=17.37, P<.01$. & & \\
\hline
\end{tabular}

7.87, $P=.02$ ) after controlling for the same covariates (Table 4).

The results from multiple regression analysis (Tables 3 and 4) support our hypothesis that overestimation of airway clearance therapy adherence is positively associated with prescribed treatment duration and lower household income. The association of overestimation with older patient age, lower parental education, and fewer adults in the household is not supported; instead, location of airway clearance therapy treatments in $>1$ household is a significant predictor of overestimated adherence.

\section{Discussion}

We compared objective and subjective reports of airway clearance therapy adherence to quantify the disagreement between these measures and to underscore the necessity of objective measures in $\mathrm{CF}$ adherence studies. According to caregiver self-reports, only $8 \%$ of subjects had low adherence, while objective data revealed $28 \%$ were low adherent. Conversely, $66 \%$ of caregiver self-reports claimed high adherence, whereas the objective data showed only $35 \%$ to be highly adherent. Nearly half (47\%) of self-reports overestimated airway clearance therapy adherence. These results indicate a large magnitude of overestimation and posit that self-reports are not a reliable assessment of airway clearance therapy adherence. Subjective reports of airway clearance therapy adherence in the home environment are problematic without adequate confirmatory technology. Although HFCWC utilization data offer a compelling measure of adherence, absence of automated, direct data transmission leads to their limited incorporation into clinical care. Equipping HFCWC vests with electronic monitoring technology is a feasible advancement that allows real-time assessment of adherence for clinical or research purposes. HFCWC vest manufacturers have begun incorporating wireless connectivity into vests (eg, Hill-Rom's VisiVest, Electromed's SmartVest Connect, and RespirTech's InCourage). This effort will be most successful if manufacturers, insurance companies, health care providers, and $\mathrm{CF}$ stakeholders work to make the new, connected devices available to all patients quickly, without extensive wait periods for those who already own a non-connected vest. Programs to ensure that vest data are shared with and effectively used by patients and clinicians will also be necessary.

As with clinical practice, most research of airway clearance therapy adherence has also relied on self-reports. We are aware of only one published study that similarly reported a gap between subjective and objective measures..$^{15}$ No prior research has identified sources of this disagreement. Our study extends the $\mathrm{CF}$ adherence literature by investigating predictors of adherence overestimation. We show that multiple locations of airway clearance therapy and prescribed daily airway clearance therapy duration $\geq 60 \mathrm{~min}$ are associated with increased odds of overestimation. Among those with prescribed daily airway clearance therapy of $\geq 60 \mathrm{~min}$, lower income $(<\$ 50,000 / \mathrm{y})$ is a risk factor for overestimation. These findings point to the importance of the caregiver environment for adherence to airway clearance therapy. Our prior research similarly identified that family structure and access to financial resources play an important role in airway clearance therapy adherence. ${ }^{16}$ Because low-income children and those who receive care in multiple households are at increased risk of overestimating adherence, they should be prioritized recipients of interventions to collect objective airway clearance therapy adherence data.

Objective and self-reported adherence tap different behavioral constructs and measure different phenomena. ${ }^{20}$ Self-reported adherence essentially is a measure of one's perception of adherence. Self-reports reflect one's perceived sense of control, ${ }^{21}$ self-esteem, ${ }^{22}$ and self-efficacy, ${ }^{23}$ as well as one's knowledge about the prescribed treatment regimen. ${ }^{24}$ One of the difficulties in airway clearance therapy adherence research is determining what has been prescribed, and this is further complicated by occasional changes in prescribed regimen due to pulmonary exacerbation or bacterial acquisition. If a written plan is not provided at each out-patient or in-patient visit, it is difficult to assess if the patient and family understand correctly what has been prescribed. As reported previously, written treatment plans are not always offered to families of patients with CF. ${ }^{24}$ Unfortunately, the Treatment Adherence Questionnaire-CF does not include a question to determine what the respondent believes the prescribed regimen to be. To detect discrepancies between perceived prescribed regimen and what was actually prescribed, a written airway clearance therapy plan should be provided.

Our study has several limitations. This is a single-center sample, which limits the generalizability of findings. The relatively high objective adherence rate (61\%) compared to adherence rates estimated in the literature $(40-47 \%$ for children with $\mathrm{CF})^{13}$ may reflect changed adherence behav- 
ior due to the awareness of being observed. Nevertheless, the rate is consistent with adherence rates published in 2 other airway clearance therapy studies $(69 \%$ and $58 \%$, respectively). ${ }^{12,15}$ Another limitation is that utilization data from the HFCWC vests were collected by study staff over the telephone because the vests in the study were not equipped for direct data transmission. Caregivers were not notified when study staff would call to record a reading, either at baseline or follow-up, and on many occasions the follow-up reading was provided by a different caregiver than the baseline reading. Despite these measures to rule out information bias, the potential for inaccurate utilization data exists. Direct data transmission from HFCWC devices is preferred when possible. In addition, the study staff did not verify whether HFCWC pressure and frequency settings matched prescribed settings. It is also possible for patients to let the equipment run without doing the treatment. Even wireless-connected vests leave room for errors or intentional misuse, such as turning the device on without wearing it. Integration of sensors for pressure and human capacitance will be necessary to guarantee proper wear and to safeguard against misuse.

\section{Conclusions}

Caregiver self-reports overestimated actual adherence to airway clearance therapy in pediatric patients with $\mathrm{CF}$. As the magnitude of overestimation is large and is present in nearly half of caregivers, self-reports are not an accurate measure of adherence. Multiple treatment locations and higher prescribed treatment duration increase the odds of adherence overestimation. Among subjects with prescribed treatments of at least 60 min daily, overestimation increased with lower income. Objective data from HFCWC equipment should be used in CF care, particularly with patients who receive care in multiple low-income households.

\section{REFERENCES}

1. Haynes RB, Taylor DW, Sackett DL. Compliance in health care. Baltimore MD: Johns Hopkins University Press; 1979.

2. Morse JM, Mitcham C, Hupcey JE, Tason MC. Criteria for concept evaluation. J Adv Nurs 1996;24(2):385-390.

3. Hommel KA, Greenley RN, Maddux MH, Gray WN, Mackner LM. Self-management in pediatric inflammatory bowel disease: a clinical report of the North American Society for Pediatric Gastroenterology, Hepatology, and Nutrition. J Pediatr Gastroenterol Nutr 2013;57(2): 250-257.

4. Collaco JM, Kole AJ, Riekert KA, Eakin MN, Okelo SO, McGrathMorrow SA. Respiratory medication adherence in chronic lung disease of prematurity. Pediatr Pulmonol 2012;47(3):283-291.

5. Modi AC, Lim CS, Yu N, Geller D, Wagner MH, Quittner AL. A multi-method assessment of treatment adherence for children with cystic fibrosis. J Cyst Fibros 2006;5(3):177-185.

6. Hommel KA, Davis CM, Baldassano RN. Objective versus subjective assessment of oral medication adherence in pediatric inflammatory bowel disease. Inflamm Bowel Dis 2009;15(4):589-593.
7. Cook CL, Wade WE, Martin BC, Perri M, 3rd. Concordance among three self-reported measures of medication adherence and pharmacy refill records. J Am Pharm Assoc (2003) 2005;45(2):151-159.

8. Eakin MN, Bilderback A, Boyle MP, Mogayzel PJ, Riekert KA. Longitudinal association between medication adherence and lung health in people with cystic fibrosis. J Cyst Fibros 2011;10(4):258-264.

9. DiMatteo MR, Giordani PJ, Lepper HS, Croghan TW. Patient adherence and medical treatment outcomes: a meta-analysis. Med Care 2002;40(9):794-811.

10. Cystic Fibrosis Foundation Patient Registry: 2013 Annual Data Report to Center Directors. Bethesda, Maryland:Cystic Fibrosis Foundation;2014. https://www.cff.org/2013_CFF_Annual_Data_Report_to_ the_Center_Directors.pdf.

11. Llorente RPA, Garcia CB, Martin JJD. Treatment compliance in children and adults with Cystic Fibrosis. J Cyst Fibros 2008;7(5): 359-367.

12. Sontag MK, Quittner AL, Modi AC, Koenig JM, Giles D, Oermann $\mathrm{CM}$, et al. Lessons learned from a randomized trial of airway secretion clearance techniques in cystic fibrosis. Pediatr Pulmonol 2010; 45(3):291-300.

13. Quittner AL, Drotar D, Ievers-Landis C. Adherence to medical treatments in adolescents with cystic fibrosis: the development and evaluation of family based interventions. In: Drotar D, editors. Promoting adherence to medical treatment in childhood chronic illness: concepts, methods, and interventions. Hillsdale, NJ: Erlbaum Associates; 2000.

14. Daniels T, Goodacre L, Sutton C, Pollard K, Conway S, Peckham D. Accurate assessment of adherence: self-report and clinician report vs electronic monitoring of nebulizers. Chest 2011;140(2):425-432.

15. Mikesell CL, Kempainen RR, Laguna TA, Menk JS, Wey AR, Gaillard PR, et al. Objective measurement of adherence to out-patient airway clearance therapy by high-frequency chest wall compression in cystic fibrosis. Respir Care 2017;62(7):920-927.

16. Oates GR, Stepanikova I, Gamble S, Gutierrez HH, Harris WT. Adherence to airway clearance therapy in pediatric cystic fibrosis: socioeconomic factors and respiratory outcomes. Pediatr Pulmonol 2015;50(12):1244-1252.

17. Quittner AL, Modi AC, Lemanek KL, Ievers-Landis CE, Rapoff MA. Evidence-based assessment of adherence to medical treatments in pediatric psychology. J Pediatr Psychol 2008;33(9):916-936.

18. Modi AC, Cassedy AE, Quittner AL, Accurso F, Sontag M, Koenig JM, et al. Trajectories of adherence to airway clearance therapy for patients with cystic fibrosis. J Pediatr Psychol 2010;35(9):1028-1037.

19. Wang XB, Dockery DW, Wypij D, Fay ME, Ferris BG. Pulmonary function between 6 and 18 years of age. Pediatr Pulmonol 1993; 15(2):75-88.

20. Jerant A, DiMatteo R, Arnsten J, Moore-Hill M, Franks P. Selfreport adherence measures in chronic illness: retest reliability and predictive validity. Med Care 2008;46(11):1134-1139.

21. Cecere LM, Slatore CG, Uman JE, Evans LE, Udris EM, Bryson CL, et al. Adherence to long-acting inhaled therapies among patients with chronic obstructive pulmonary disease (COPD). COPD 2012;9(3):251258.

22. Burge S, White D, Bajorek E, Bazaldua O, Trevino J, Albright T, et al. Correlates of medication knowledge and adherence: findings from the residency research network of South Texas. Fam Med 2005;37(10):712-718.

23. Ricker JH, Delamater AM, Hsu J. Correlates of regimen adherence in cystic fibrosis. J Clin Psychol Med Settings 1998;5(2):159-172.

24. Modi AC, Quittner AL. Barriers to treatment adherence for children with cystic fibrosis and asthma: what gets in the way? J Pediatr Psychol 2006;31(8):846-858. 